\section{Using Mini- Rockwool Blocks as Growing Media for Limited-cluster Tomato Production}

\author{
Logan S. Logendra, \\ Thomas J. Gianfagna, and \\ Harry W. Janes
}

Additional IndeX wORds. Lycopersicon esculentum, hydroponics, ebb and flood

Summary. Rockwool is an excellent growing medium for the hydroponic production of tomato; however, the standard size rockwool blocks [ $4 \times 4 \times$ 2.5 inches $(10 \times 10 \times 6.3 \mathrm{~cm})$ or $3 \times 3$ $\times 2.5$ inches $(7.5 \times 7.5 \times 6.3 \mathrm{~cm})]$ are expensive. The following experiments were conducted with less expensive minirock wool blocks (MRBs), on rayon polyester material (RPM) as a bench top liner, to reduce the production cost of tomatoes (Lycopersicon esculentum) grown in a limitedcluster, ebb and flood hydroponic cultivation system. Fruit yield for single-cluster plants growing in MRBs $[2 \times 2 \times 1.6$ inches $(5 \times 5 \times 4 \mathrm{~cm})$ and $1.6 \times 1.6 \times 1.6$ inches $(4 \times 4 \times 4 \mathrm{~cm})]$ was not significantly different from plants grown in larger sized blocks ( 3 $\times 3 \times 2.5$ inches). When the bench top was lined with RPM, roots penetrated the RPM, and an extensive root mat developed between the RPM and the bench top. The fruit yield from plants on RPM was significantly increased compared to plants without RPM due to increases in fruit size and fruit number. RPM also significantly reduced the incidence of blossom-end rot. In a second experiment, singleand double-cluster plants were grown on RPM. Fruit yield for doublecluster plants was $40 \%$ greater than for single-cluster plants due to an

Plant Science Department, Rutgers University, 59 Dudley Road, New Brunswick, NJ 08901-8520.

The cost of publishing this paper was defrayed in part by the payment of page charges. Under postal regula tions, this paper therefore must be hereby marked advertisement solely to indicate this fact. increase in fruit number, although the fruit were smaller in size. As in the first experiment, fruit yield for all plants grown in MRBs was not significantly different from plants grown in the larger sized blocks. MRBs and a RPM bench liner are an effective combination in the production of limited-cluster hydroponic tomatoes.

$\mathrm{H}$ ydroponics is the technique of raising plants in a soilless medium with added nutrient solution. Many countries are involved in greenhouse vegetable crop production. Holland $[10,000$ acres $(4,049$ ha) $]$, England $[4,200$ acres ( 1,700 ha $)]$, Canada [990 acres (40l ha)], and the U.S. [590 acres (239 ha)] have the most acres under hydroponic cultivation (Resh, 1995). Recently, there have been significant improvements in hydroponic systems due to extensive research and development in the U.S. and Europe (Jensen, 1996). There are several benefits to hydroponic culture over soil production such as: higher quality and yield, minimal leaching of fertilizer to ground water, less fertilizer and water use, and easy management of the crop by computer automation (Resh, 1995). Hydroponics is the most common means of producing fresh vegetables in arid regions and countries that lack arable land.

Ebb and flood is one type of hydroponic system in which plants are grown in a bench or shallow bed and irrigated several times per day with fertilizer solution that is drained to a storage tank for reuse. Currently, vegetables (Burns, 1996; Terabayashi et al., 1997), ornamentals (Anderson and Woods, 1999; Bredmose, 1998), and herbs (JeongHwa et al., 1999; Yoma et al., 1998) are produced using ebb and flood systems in greenhouses.

Many different types of growing media are used to grow plants in the ebb and flood system including: pots containing soilless mix, perlite, peat, vermiculite, coconut-coir, and rockwool (RW) (Caraveo Lopez et al., 1996; Fisher et al., 1990; Stamps and Evans, 1997 and Verhagen, 1993). The most important factors to be considered in the selection of a growing medium are availability, reliability, and suitability for a particular hydroponic system. Growers in many countries use RW since it is sterile, inert, and light- weight, with high porosity and excellent water holding capacity. RW is made by melting a mixture of volcanic rock, limestone, and coke at a temperature of $2912{ }^{\circ} \mathrm{F}\left(1600{ }^{\circ} \mathrm{C}\right)$, and then cooling and spinning the mixture into fibers (Fonteno and Nelson, 1990).

The main drawback of $\mathrm{RW}$ is the high cost of the material. In traditional multicluster tomato production, standard size RW blocks $(4 \times 4 \times 2.5$ inches or $3 \times 3 \times 2.5$ inches) are placed on top or inserted within a $36 \times 6 \times 3$ inch $(90$ $\times 15 \times 7.5 \mathrm{~cm})$-RW slab. Considering the cost factor of the RW, many growers are beginning to explore the possibilities of raising crops in smaller RW containers (Jensen, 1996). Several authors compared tomato plants grown in small vs. larger containers in hydroponic culture. Plants in small containers had lower leaf area and plant dry weight (Peterson et al., 1991), reduced node number and plant height (Ruffet al., 1987), and decreased shoot and root growth (Hameed et al., 1987), all probably due to a restriction in root growth. Root restriction causes a reduction in shoot and root weight, and inhibits leaf expansion in cucumber (Cucumis sativa) (Robbins and Pharr, 1988), results in dwarf plants with short internodes and smaller root systems in bean (Phaseolus vulgaris) (Carmi and Heuer, 1981), reduces growth rate and plant size in peach (Prunus persica) (Richard and Rowe, 1977), and decreases leaf growth in cotton (Gossypium hirsutum L.) (Mutsaers, 1983). However, in our previous study, we demonstrated using only a standard sized RW block ( 3 $\times 3 \times 2.5$ inches) and rayon polyester material (RPM) as an additional substrate for roots, that the single-cluster tomato can be grown successfully with high yield (Logendra and Janes, 1999). Presently, this system is being tested in a 1-acre greenhouse at the New Jersey Eco-Complex in Burlington, N.J. The following study was initiated to evaluate even smaller minirock wool blocks (MRBs) as a cost-effective growing medium for single or double-cluster tomato production in an ebb and flood hydroponic system.

\section{Materials and methods}

Three different MRBs (Agro-Dynamics, East Brunswick, N.J.), MM $50 / 40(2 \times 2 \times 1.6$ inches $)$, MM 40/ $40(1.6 \times 1.6 \times 1.6$ inches $)$, and $\mathrm{AO}$ 
$50 / 40(2 \times 2 \times 1.6$ inches $)$, along with a standard sized RW block, DM4 42/ $40(3 \times 3 \times 2.5$ inches $)$, were used. MM 50/40, MM 40/40, AO 50/40 and DM4 42/40 are Agro-Dynamics, Inc. product numbers. All RW blocks were individually wrapped in ultraviolet resistant plastic around the four vertical sides, except for AO 50/40, which was not wrapped. Each MRB has a small hole in the center to accommodate the seed, whereas DM4 42/40 RW has a hole $[1.7 \times 1.6$ inches $(4.3 \times 4 \mathrm{~cm})]$ large enough to accommodate an RW plug [AO 36/40; $1 \times 1 \times 1.6$ inches $(2.5 \times$ $2.5 \times 4 \mathrm{~cm})]$ containing a seed. 'Laura' tomato was direct-seeded to MRBs and RW plugs and kept wet until seed germination. Seedlings were fertilized once daily with hydrosol-calcium nitrate solution $\left(1: 1,2.3 \mathrm{mS} \cdot \mathrm{cm}^{-1}\right)$ (E.C. Geiger, Inc., Harleysville, Pa.). Two-week-old seedlings in RW plugs were placed in DM4 42/40 RW blocks. Both MRBs and DM4 42/40 blocks were placed on the bench over RPM at an equidistant spacing of $8 \times 8$ inches $(20 \times 20 \mathrm{~cm})$ and irrigated with the same frequency and concentration. The irrigation cycle was increased to twice daily beginning with the fifth week. At the end of the fifth week, plants were randomly assigned with a spacing of $12 \times 12$ inches $(30 \times 30$ $\mathrm{cm}$ ) on four experimental benches with RPM unless specified otherwise. Seedlings were irrigated six times daily with nutrient solution $\left(2.3-2.5 \mathrm{mS} \cdot \mathrm{cm}^{-1}\right)$. Plants were topped by soft pinching the terminal bud of the main stem, leaving two leaves above the first or second cluster as per each experiment. Crops were supported on the bench by one or two horizontal layers of wire mesh netting [12-gauge, galvanized with $6 \times 8$ inch $(15 \times 20 \mathrm{~cm})$ grids]. Side shoots were manually pruned when required. Pollination was carried out with a leafblower, once daily, during the flowering period. Fruits were harvested at the firm red stage. Plant height at harvest, days to anthesis of the first cluster, total fruit number and weight, shoot fresh weight, harvest index (fruit weight/ fruit weight + shoot weight, on a fresh weight basis), and any physiological disorders were recorded and evaluated. Supplemental lighting was provided from high-pressure sodium lamps at an intensity of $80 \mu \mathrm{mol} \cdot \mathrm{m}^{-2} \cdot \mathrm{s}^{-1}$ for 16 $\mathrm{h}$ from 0500 to $2100 \mathrm{HR}$, if the natural light intensity was less than 800 $\mu \mathrm{mol} \cdot \mathrm{m}^{-2} \cdot \mathrm{s}^{-1}$. The greenhouse was maintained at $75^{\circ} \mathrm{F} / 68^{\circ} \mathrm{F}\left(24^{\circ} \mathrm{C} / 20\right.$ $\left.{ }^{\circ} \mathrm{C}\right)$ of day/night temperature. The experiments were conducted at the New Jersey Agricultural Experiment Station greenhouse, Rutgers University, New Brunswick, N.J.

EXPERIMENT 1. Evaluation of different sized RW blocks as growing medium for single-cluster tomato production, with and without RPM.

The experimental design was a split plot with the main plot (+RPM or RPM) and subplots (different sized RW blocks) in eight replicated blocks with one plant/treatment. One half of each bench was covered with RPM. There were two replicated blocks on each bench and the main and subplot treatments were randomly assigned. A total of four benches were used and the experiment was repeated once with similar results.

EXPERIMEnt 2. Evaluation of different sized RW blocks for double-cluster tomato production.

The experimental design was a split plot with the main plot (one or two clusters) and subplots (different sized RW blocks) in nine replicated blocks with two plants/treatment. RPM was used for all treatments. Plants were topped leaving two leaves above either one or two clusters. The experiment was repeated once with similar results.

\section{Results and discussion}

In Expt. 1, plants grown in MRBs with RPM had excellent root growth. The roots penetrated the RPM, forming a thick mat between the RPM and the bench top (Fig. 1). This created an additional reservoir for retaining nutri- ent solution for an extended period of time. In contrast, roots of plants without RPM, were restricted to the RW blocks and adventitious roots that appeared along edges of the blocks were either discolored or light brown in color. Plants without RPM, beginning from the time of anthesis of the first flower, showed signs of wilting or water stress, especially during midday. This resulted in a $28 \%$ reduction in shoot fresh weight, a $62 \%$ reduction in fruit number, and a $67 \%$ reduction in fruit yield (Table 1 ). Plants grown without RPM also had significant decreases in average fruit weight and harvest index. There were no differences, however, in fruit weight, fruit number, or harvest index among the various sized RW blocks, demonstrating that MRBs can be used for single-cluster tomato production.

Our findings were similar to the study by Ruff et al. (1987) in which 'Better Bush' tomato in a root-restricted environment had significantly lower fruit number and lower fresh and dry weight of mature fruits. A possible explanation for the poor fruit yield of plants without the RPM may be that a limited root system is unable to provide an adequate supply of nutrients, growth substances, and water to the fruit. Without the RPM, $66 \%$ of harvested fruits were affected with blossom-end rot. This was probably due to poor root growth leading to inefficient and insufficient absorption of calcium and water from the nutrient solution. Many authors have demonstrated the importance of calcium and water uptake for the preven-

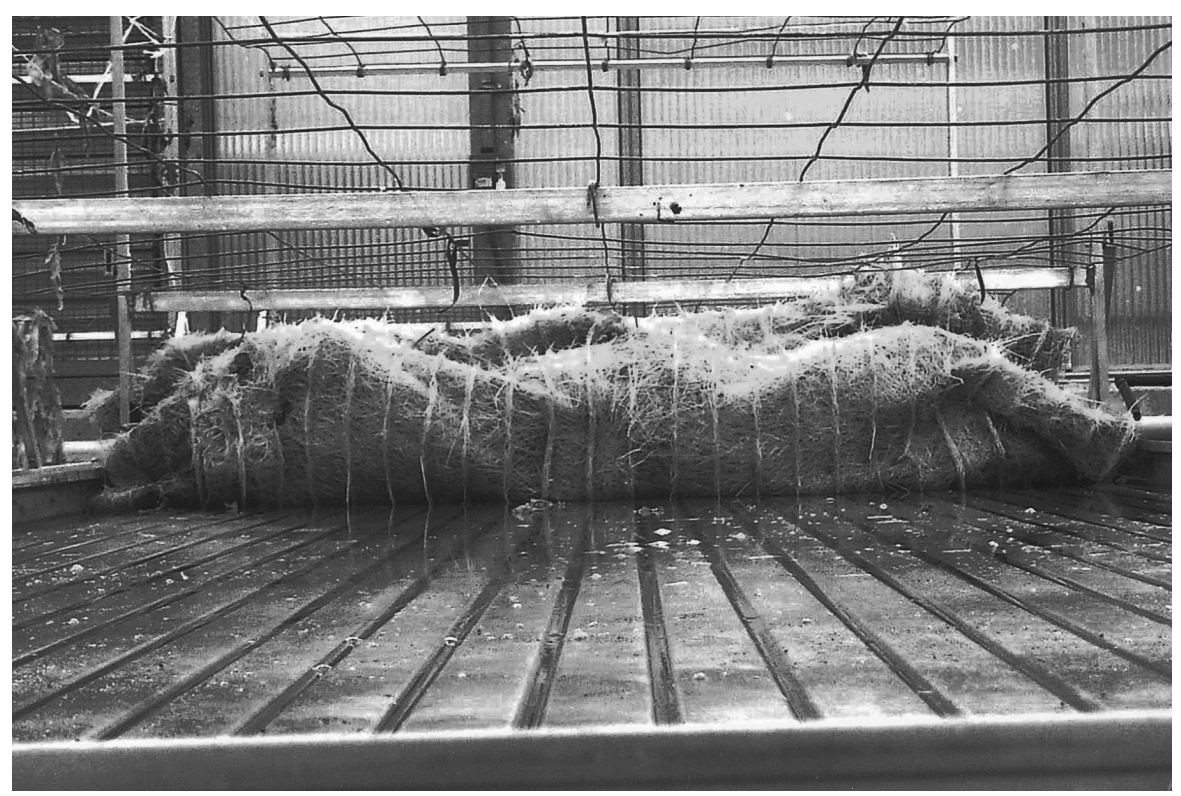

Fig. 1. Rayon polyester material with the roots rolled up at the end of harvest. 


\begin{tabular}{|c|c|c|c|c|c|c|c|c|}
\hline Treatment & $\begin{array}{c}\text { Anthesis } \\
\text { of first } \\
\text { flower } \\
\text { (d) }\end{array}$ & $\begin{array}{l}\text { Fruit/ } \\
\text { plant } \\
\text { (no.) }\end{array}$ & $\begin{array}{c}\text { Fruit } \\
\text { wt/ } \\
\text { plant } \\
(g)^{\mathrm{z}}\end{array}$ & $\begin{array}{c}\text { Avg } \\
\text { fruit } \\
\text { wt } \\
(\mathrm{g}) \\
\end{array}$ & $\begin{array}{c}\text { Fruit } \\
\text { with } \\
\text { blossom- } \\
\text { end } \\
\text { rot }(\%) \\
\end{array}$ & $\begin{array}{c}\text { Plant } \\
\text { ht at } \\
\text { harvest } \\
(\mathbf{c m})^{\mathbf{y}}\end{array}$ & $\begin{array}{c}\text { Shoot } \\
\text { fresh } \\
\text { wt } \\
(\mathrm{g}) \\
\end{array}$ & $\begin{array}{c}\text { Harvest } \\
\text { index }^{x} \\
\end{array}$ \\
\hline \multicolumn{9}{|l|}{ Rock wool $(\text { RW })^{\mathrm{w}}$} \\
\hline MM 40/40 & $44.3 \mathrm{~b}^{\mathrm{v}}$ & 4.2 & 907.2 & $206.2 \mathrm{~b}$ & 32 & $60.9 \mathrm{bc}$ & $424.9 \mathrm{~b}$ & 0.57 \\
\hline DM4 42/40 & $44.3 \mathrm{~b}$ & 3.8 & 885.5 & $236.4 \mathrm{a}$ & 37 & $58.8 \mathrm{c}$ & $551.4 \mathrm{a}$ & 0.53 \\
\hline \multicolumn{9}{|c|}{ Rayon polyester material (RPM) } \\
\hline No & 44.8 & $2.1 \mathrm{~b}$ & $419.3 \mathrm{~b}$ & $202.0 \mathrm{~b}$ & $66 \mathrm{a}$ & 61.0 & $386.4 \mathrm{~b}$ & $0.38 \mathrm{~b}$ \\
\hline Yes & 44.5 & $5.5 \mathrm{a}$ & $1255.3 \mathrm{a}$ & $232.0 \mathrm{a}$ & $14 \mathrm{~b}$ & 63.1 & $535.3 \mathrm{a}$ & $0.69 \mathrm{a}$ \\
\hline \multicolumn{9}{|l|}{ Significance } \\
\hline
\end{tabular}

Table 2. Growth and yield of single or double-cluster 'Laura' tomato in minirock wool blocks and standard size block DM4 42/40 (3 $\times 3 \times 2.5$ inches) with rayon polyester material.

\begin{tabular}{|c|c|c|c|c|c|c|c|}
\hline Treatment & $\begin{array}{l}\text { Anthesis of } \\
\text { first flower } \\
\text { (d) }\end{array}$ & $\begin{array}{l}\text { Fruit/ } \\
\text { plant } \\
\text { (no.) } \\
\end{array}$ & $\begin{array}{c}\text { Fruit wt/ } \\
\text { plant } \\
(\mathrm{g})^{\mathrm{z}}\end{array}$ & $\begin{array}{c}\text { Avg } \\
\text { fruit wt } \\
\text { (g) } \\
\end{array}$ & $\begin{array}{c}\text { Plant ht at } \\
\text { harvest } \\
(\mathrm{cm})^{\mathrm{y}}\end{array}$ & $\begin{array}{c}\text { Shoot } \\
\text { fresh wt } \\
\text { (g) }\end{array}$ & $\begin{array}{c}\text { Harvest } \\
\text { index }^{x}\end{array}$ \\
\hline \multicolumn{8}{|l|}{ Rock wool (RW)w } \\
\hline MM $40 / 40$ & 41.4 & 6.2 & 976.3 & 168.1 & $77.9 \mathrm{a}$ & $483.9 \mathrm{~b}$ & 0.66 \\
\hline MM 50/40 & 40.8 & 6.4 & 1113.5 & 175.6 & $77.4 \mathrm{a}$ & $472.2 \mathrm{~b}$ & 0.68 \\
\hline AO $50 / 40$ & 41.8 & 6.1 & 1062.8 & 183.1 & $76.9 \mathrm{a}$ & $572.7 \mathrm{a}$ & 0.63 \\
\hline Single & 41.2 & $4.6 \mathrm{~b}^{\mathrm{v}}$ & $896.0 \mathrm{~b}$ & $201.9 \mathrm{a}$ & $67.0 \mathrm{~b}$ & $496.1 \mathrm{~b}$ & $0.63 \mathrm{~b}$ \\
\hline Double & 41.5 & $7.9 \mathrm{a}$ & $1251.5 \mathrm{a}$ & $157.3 \mathrm{~b}$ & $86.5 \mathrm{a}$ & $559.8 \mathrm{a}$ & $0.68 \mathrm{a}$ \\
\hline \multicolumn{8}{|l|}{ Significance } \\
\hline RW & NS & NS & NS & NS & * & $* * *$ & NS \\
\hline Clusters & NS & ** & $* * *$ & $* *$ & $* * *$ & * & $*$ \\
\hline
\end{tabular}

$\mathrm{z} 28.35 \mathrm{~g}=1.0 \mathrm{oz}$

$\mathrm{y} 2.54 \mathrm{~cm}=1.0$ inch.

${ }^{\mathrm{x}}$ Fruit weight/total plant weight.

${ }^{w}$ MM $40 / 40(1.6 \times 1.6 \times 1.6$ inches $)$, MM 50/40 $(2 \times 2 \times 1.6$ inches $)$, AO 50/40 $(2 \times 2 \times 1.6$ inches, not wrapped $)$, DM4 $42 / 40(3 \times 3 \times 2.5$ inches $)$.

"Values followed by the same letter within columns are not significantly different according to the least significant test at $P<0.05$.

Ns, $,{ }^{\star \star \star},{ }^{\star \star \star}$ Nonsignificant or significant at $P<0.05,0.01$, or 0.001 , respectively.

tion of blossom-end rot in tomato fruits (Franco et al., 1998; He et al., 1999; Ho et al., 1999; Ohta et al., 1999; Paiva et al., 1998; Reid et al., 1996; Wada et al., 1996).

In our study, there was no difference in the anthesis date of the first flower of the first cluster for the plants grown without RPM (Table 1), however, in cotton, Carmi (1986) and Carmi and Shalhvet (1983) found that rootrestricted plants flowered earlier than those grown in larger containers.
In Expt. 2, double-cluster tomato plants had a significantly greater harvest index, producing $72 \%$ more fruit with $40 \%$ more fruit weight compared to single-cluster plants. There were no differences, however, in fruit weight, fruit number or average fruit weight among plants grown in different sized RW blocks (Table 2). Although plants were shorter and had greater shoot fresh weight in the standard sized RW block, this did not significantly affect the harvest index (Table 1 and 2 ). These results were similar to the findings of Cooper (1972) who found that the volume of the containers in which tomato plants were grown had little influence on the partition of dry matter between cotyledons, roots, stem, and leaves.

In both experiments there were no differences in fruit yield when plants were grown in MRBs with RPM compared to a standard sized block. We observed similar results when we compared the two standard size RW blocks, DM6 $42 / 40(4 \times 4 \times 2.5$ inches $)$ and 
Fig. 2. Single and double-cluster tomato plants grown on rayon polyester material in different-sized rockwool blocks before harvest.

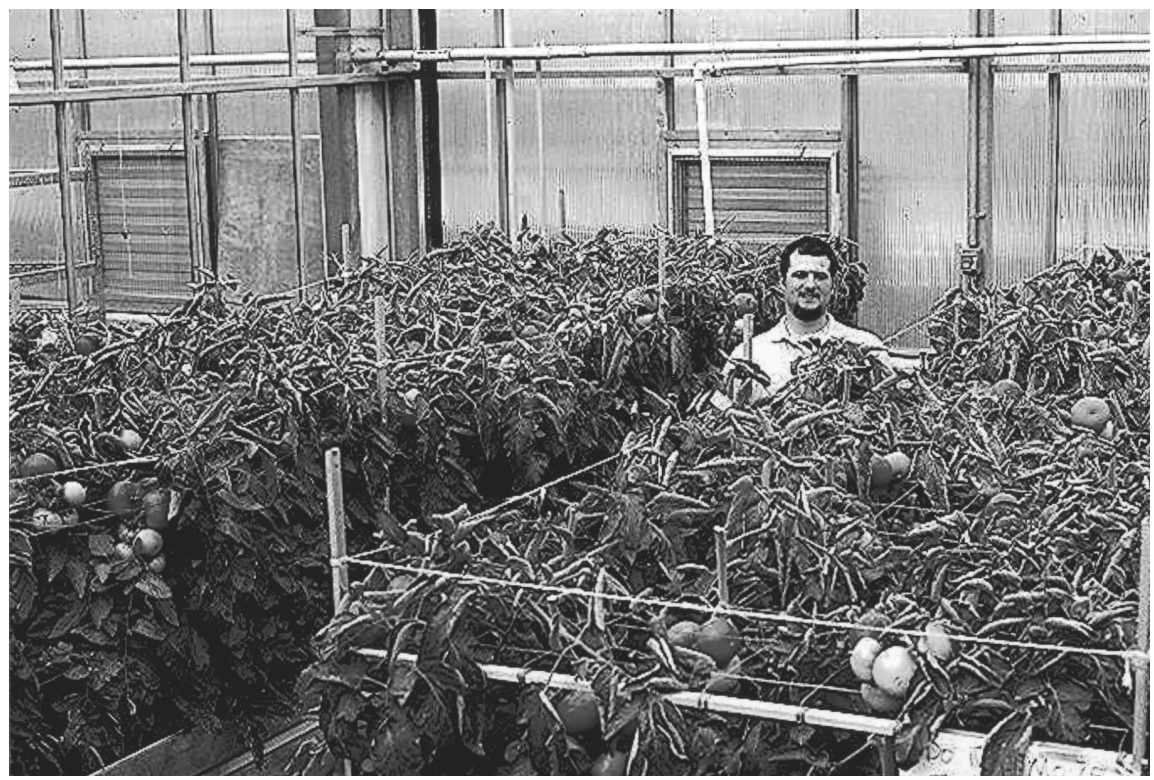

Table 3. Cost of different sized rock wool $(\mathrm{RW})$ blocks and plugs AO $36 / 40(1 \times 1 \times 1.6$ inches $)$ to produce a limitedcluster tomato crop in the ebb and flood system for a 1 -acre $(0.4-h a)$ greenhouse.

\begin{tabular}{lccc}
\hline RW blocks + plugs & $\begin{array}{c}\text { RW blocks + plugs } \\
\text { (no./acre) }\end{array}$ & $\begin{array}{c}\text { Cost/RW block + plug } \\
\mathbf{( \$ )}\end{array}$ & $\begin{array}{c}\text { Total cost of material/acre } \\
(\mathbf{\$})\end{array}$ \\
\hline DM6 42/40 + AO 36/40 & $23,298+28,227$ & $0.58+0.08$ & 15,771 \\
DM4 42/40 + AO 36/40 & $23,298+28,227$ & $0.39+0.08$ & 11,347 \\
MM 50/40 & 28,227 & 0.15 & 4,234 \\
AO 50/40 & 28,227 & 0.13 & 3,670 \\
MM 40/40 & 28,227 & 0.12 & 3,387
\end{tabular}

${ }^{2}$ DM6 42/40 (4 ×4 2.5 inches $)$, AO 36/40 $(1 \times 1 \times 1.6$ inches $)$, MM 40/40(1.6 × $1.6 \times 1.6$ inches $)$, MM 50/40 $(2 \times 2 \times 1.6$ inches $)$, AO $50 / 40(2 \times 2 \times 1.6$ inches, not wrapped $)$, DM4 $42 / 40(3 \times 3 \times 2.5$ inches $)$.

DM4 42/40 (data not shown). Our study suggests that plants can be successfully grown in smaller blocks in the ebb and flood system without yield reduction, with RPM as an additional substrate for the roots (Fig. 2). For yearround limited-cluster greenhouse tomato production (five crops per year), MRBs can substantially reduce the cost of growing media compared to the standard DM4 42/40 blocks (Table 3). Furthermore, since RW is not biodegradable, MRBs are better since there is less material for waste disposal. Considering the cost of RW blocks, MRBs should also be evaluated as the seedling block in the conventional greenhouse hydroponic tomato production system where RW slabs are used as the substrate for root growth.

\section{Literature cited}

Anderson, R.G. and T.A. Woods. 1999. An economic evaluation of single stem cut rose production. Acta Hort. 481:629-634.

Bredmose, N.B. 1998. Growth, flowering, and postharvest performance of single- stemmed rose (Rosa hybrida L.) plants in response to light quantum integral and plant population density. J. Amer. Soc. Hort. Sci. 123(4):569-576.

Burns, I.G. 1996. Nitrogen supply, growth and development. Acta Hort. 428:21-30.

Caraveo Lopez, F. de J., G.A. Baca Castillo, J.L. Tirado Torres, and F. Sanchez del Castillo. 1996. Hydroponics culture of tomato with coconut coir dust substrate, and its response to ammonium and potassium. Agrociencia 30(4):495-500.

Carmi, A. 1986. Effects of root zone volume and plant density on the vegetative and reproductive development of cotton. Field Crop Res. 13:25-32.

Carmi, A. and B. Heuer. 1981. The role of roots in control of bean shoot growth. Ann. Bot. 48:519-527.

Carmi, A. and J. Shalhevet. 1983. Root effects on cotton growth and yield. Crop Sci. 23:875-878.

Cooper, A.J. 1972. The influence of container volume, solution concentration, $\mathrm{pH}$ and aeration on dry matter partition by tomato plants in water culture. J. Hort. Sci. 47:341-347.
Fisher, D.F., G.A. Giacomelli, and H.W. Janes. 1990. A system of intensive tomato production using ebb-flood benches. Professional Hort. 4(3):99-106.

Fonteno, W.C. and P.V. Nelson. 1990. Physical properties of and plant responses to rockwool-amended media. J. Amer. Soc. Hort. Sci. 115(3):375-381.

Franco, J.A., P.J. Perez-Saura, and A. Duran. 1998. Calcium for correcting blossom-end rot in tomato. Horticultura Revista de Hortalizas, Flores y Plantas Ornamentales 126:90-92.

Hameed, M.A., J.B. Reid, and R.N. Rowe. 1987. Root confinement and its effects on the water relations, growth and assimilate partitioning of tomato (Lycopersicon esculentum Mill.). Ann. Bot. 59:685-692.

He, Y.Q., S. Terabayashi, and T. Namiki. 1999. Effect of temporary calcium deficiency on fruit growth and element concentrations in the petiole sap of tomato. Acta Hort. 481:409-415.

Ho, L.C., D.J. Hand, and M. Fussell. 1999. Improvement of tomato fruit quality by calcium nutrition. Acta Hort. 481:463-468. 
Jensen, M. 1996. Hydroponics today. Amer. Veg. Grower (September):A-D.

JeongHwa, M. YuonJa, P. KiBae, H. MooRyong, and P. JoongChoon. 1999. Growth effect of levels of nutrient solution using the ebb and flow system in 6 herbs. J. Korean Soc. Hort. Sci. 40(3):399-402.

Logendra, L.S. and H.W. Janes. 1999. Hydroponics tomato production: Growing media requirements. Acta Hort. 481:483486.

Mutsaers, H.J.W. 1983. Leaf growth in cotton (Gossypium hirsutum L.): 2. The influence of temperature, light, water stress and root restriction on the growth and initiation of leaves. Ann. Bot. 51:521-529.

Ohta, K., E. Takeda, D. Yoshioka, T. Asao, and T. Hosoki. 1999. Differences in the occurrence of blossom-end rot in cherry and large fruit tomatoes. J. Soc. High Technol. Agr. 11(1):22-25.

Paiva, E.A.S., H.E.P. Martinez, V.W.D. Casali, and L. Padilha. 1998. Occurrence of blossom-end rot in tomato as a function of calcium dose in the nutrient solution and air relative humidity. J. Plant Nutr. 21(12):2663-2670.

Peterson, T.A., M.D. Reinsel, and D.T. Krizek. 1991. Tomato (Lycopersicon esculentum Mill., cv. (Better Bush) plant response to root restriction. J. Expt. Bot. 42(243):1233-1240.

Reid, J.B., D. Winfield, I. Sorensen, and A.J. Kale. 1996. Water deficit, root demography, and the causes of internal blackening in field-grown tomatoes (Lycopersicon esculentum Mill.).Ann. Appl. Biol. 129(1):137149.

Resh, H.M. 1995. Hydroponic food production. $5^{\text {th }}$ ed. Woodbridge Press Publishing Co., Santa Barbara, Calif. p. 23-31.
Richards, D. and R.N. Rowe. 1977. Effects of root restriction, root pruning and 6benzylaminopurine on the growth of peach seedlings. Ann. Bot. 41:729-740.

Robbins, N.S. and D.M. Pharr. 1988. Effect of restricted root growth on carbohydrate metabolism and whole plant growth of CucumissativusL. Plant Physiol. 87:409413.

Ruff, M.S., D.T. Krizek, R.M. Mirecki, and D.W. Inouye. 1987. Restricted root zone volume: Influence on growth and development of tomato. J. Amer. Soc. Hort. Sci. 112(5):763-769.

Stamps, R.H. and M.R. Evans. 1997. Growth of Dieffenbachia maculata 'Camille' in growing media containing sphagnum peat or coconut coir dust. HortScience 32(5):844-847.

Terabayashi, S., T. Yoma, and T. Namiki. 1997. Root development of root crops grown in deep flow and ebb and flood culture. Environ. Control Biol. 35(2):99105.

Verhagen, J.B.G.M. 1993. Peat as a substrate for year round chrysanthemum growing. Acta Hort. 342:221-227.

Wada, T., H. Ikeda, M. Ikeda, and H. Furukawa. 1996. Effects of foliar application of calcium solutions on the incidence of blossom-end rot of tomato fruit. J. Jpn. Soc. Hort. Sci. 65(3):553-558.

Yoma, T., C. Hasegawa, M. Minami, and M. Sugino. 1998. Production of medicinal plants by hydroponics. part 6. Effects of plant density on the growth and yield of Angelica acutiloba Kitagawa plants cultivated in ebb and flow system. J. Soc. High Technol. Agr. 10(4):221-224 